NASA Technical Memorandum 100281

\title{
Simplified Procedures for Designing Composite Bolted Joints
} (NASA-TH-100281) SIAPLIFIBD PROCEDORES FOR
DESIGHING COHPOSITE BOLTED JOINTS (AASA)
$15 \mathrm{P}$
$888-15020$

Onclas

Christos C. Chamis

Lewis Research Center

Cleveland, Ohio

Prepared for the

43rd Annual Conference of the Society of the Plastics Industry Cincinnati, Ohio, February 1-5, 1988 
SIMPLIFIED PROCEDURES FOR DESIGNING COMPOSITE BOLTED JOINTS

Christos C. Chamis

National Aeronautics and Space Administration

Lewis Research Center

Cleveland, Ohio 44135

\section{SUMMARY}

Simplified procedures (methods) are described to design/analyze single and multibolt composite joints. Numerical examples illustrate the use of these methods. Factors affecting composite bolted joints are summarized. References are cited where more detailed discussion are presented on specific aspects of composite bolted joints. Design variables associated with these joints are summarized in the appendix.

\section{INTRODUCTION}

The structural integrity of composite structures is often times determined by the integrity and durability of their respective joints. The two general classes of joints are mechanical fasteners and adhesive bonding. The integrity of the mechanical fastener joints depends mainly on the local laminate bearing strength, while that for adhesively bonded joints, depends mainly on local interlaminar shear strength.

Composite joints have been extensively investigated in recent years. Results of these investigations are reported, in part, in symposium proceedings (refs. 1 and 2). Helpful recommendations for design practice for select composite joints are included in reference 3 . Analysis methods for detailed stress calculations are described in reference 4.

Recent research at the NASA Lewis Research Center focuses on developing simplified methods for predicting microstresses and local laminate strengths including interlaminar strengths (refs. 5 and 6 ). In this report these methods are used to design bolted joints for composite structures. The objective of the paper is to describe these methods and outline a step-by-step procedure for their use in the preliminary design phase of composite joints. Several numerical examples are included to illustrate applications of these simplified methods to select bolted composite joints. Typical design variables are summarized in the appendix for convenience.

\section{COMPOSITE BOLTED JOINTS: FAILURE MODES AND ANALYSIS}

Bolted joints are designed to resist certain select failure modes during the preliminary design phase. These select failure modes are those most commonly occurring in practical applications. They include: (1) local bearing, (2) net tension, (3) wedge-type splitting, (4) shear-out, and (5) tension with shear-out. These select failure modes and the approximate equations used to quantify them are described below in detail. 


\section{Local Bearing Failure Modes}

Local bearing failure modes are characterized by a local laminate compressive failure caused by the bolt diameter which tends to crush the composite material. A schematic of these types of failure modes is shown in figure 1. The schematic which is used to derive the equation and the respective equation are also shown in figure 1 . The requisite variables to design against this failure mode are: (1) bolt diameter (d), (2) laminate thickness $\left(t_{c}\right)$, and ( 3 ) laminate compressive strength parallel to the bolt force $(S C \times \times C$ ). Use of the equation ( $f i g .1(a)$ ) is illustrated in the following example.

Example 1. Calculate the local average bearing stress $\left(\sigma_{C x x}\right)$ in a $[0 \pm 45 / 0 / 90]_{S}$ AS/E laminate induced by a 1/4-in. diameter titanium bolt with a $10 \overline{0} 0 \mathrm{lb}$ load. These referred to herein as the composite bolted joint specified conditions. To perform this calculation, we first solve the equation in figure $1(a)$ for $S_{C \times x C}$ and replace $S$ with $\sigma$

$$
\sigma_{c x X}=\frac{F}{d t_{C}}
$$

where $F$ is $1000 \mathrm{lb}, d$ is $1 / 4$ in., and $t_{c}$ is 0.05 in. (10 piles at $0.005 \mathrm{in.} / \mathrm{p}(\mathrm{y})$. Using these values in the equation we obtain

$$
\sigma_{c x x}=\frac{10001 b}{(0.25 \text { by } 0.05)}=80000 \mathrm{psi}
$$

The corresponding laminate compressive strength $\left(S_{C \times x}\right)$ from table I is $79700 \mathrm{psi}$. The margin-of-safety (MOS) against local bearing failure is

$$
\operatorname{MOS}=\left(\frac{S_{C \times X C}}{\sigma_{C \times X}}\right)-1=\left(\frac{79700 p s i}{80000 p s i}\right)-1=-0.004
$$

Therefore, this bolted connection will barely fail in local bearing.

\section{Net Tension Failure Modes}

Tensile failure modes are characterized by "net-tension" laminate fracture. A schematic of these types of failure modes is shown in figure $1 \mathrm{~b}$ where the schematic used to derive the governing equation and the equation are also shown. The requisite variables to design against this failure mode are: (1) net section width $(w-d)$, (2) laminate thickness $\left(t_{c}\right)$ and (3) laminate tensile strength $\left(S_{C \times x T}\right)$. Use of the equation ( $f i g .1 b$ ) is illustrated in the following example.

Example 2. Calculate the net section stress $\left(\sigma_{c x x}\right)$ at the bolt hole edge for the composite bolted joint specified conditions in example 1 with bolt spacing (w) equal $1.0 \mathrm{in}$. To perform this calculation we solve the equation in figure ib for $S_{C X X T}$.

$$
\frac{F}{\left[(w-d) t_{C}\right]}
$$

where $F$ is $1000 \mathrm{lb} / \mathrm{in} ., w$ is $1.0 \mathrm{in.}, d$ is $1 / 4 \mathrm{in}$. , and $t_{c}=0.05 \mathrm{in}$. Using these values in the equation we obtain 


$$
\sigma_{\text {cxx }}=\frac{1000 \mathrm{lb}}{[(1.00 \mathrm{in.}-0.25 \mathrm{in.}) \times 0.05 \mathrm{in.}]}=26700 \mathrm{psi}
$$

The corresponding laminate tensile strength ( $S_{C x x}$ ) from table I is 79200 psi. The margin of safety is

$$
\text { MOS }=\left(\begin{array}{lll}
\frac{79}{2} 200 \text { psi } \\
26700 \text { psi }
\end{array}\right)-1=1.97 \quad 0 . K .
$$

Therefore this composite bolted joint will not fail in net tension.

\section{Wedge-Type Splitting Failure Modes}

Wedge-type splitting failure modes in composite bolt joints are characterized by laminate splitting which starts at the local bearing point and propagates to the free edge. These failure modes are caused by the lateral pressure of the bolt against the laminate. The failure mode is shown in figure $1(c)$ where the schematic used to derive the equation and the equation are also shown. The requisite variables to design against this failure mode are: (1) bolt diameter (d), (2) laminate the thickness ( $\left.t_{c}\right)$ (2) edge distance (e) and (3) laminate transverse tensile strength (ScyyT). The following example illustrates use of the equation in figure $1(c)$.

Example 3. Calculate the transverse splitting stress $\left(\sigma_{c y y}\right)$ for the composite bolted joint specified conditions in example 1 with e equal to 1.0 in. To perform this calculation we solve the equation in figure $1(\mathrm{c})$ for Scyyt and replace $S$ with $\sigma$

$$
\sigma_{c y y}=\frac{2 F}{\left[(2 e-d) t_{c}\right]}
$$

where $F$ is $1000 \mathrm{lb}$, e $=1.0 \mathrm{in} ., d$ is $1 / 4 \mathrm{in}$. and $t_{c}$ is $0.05 \mathrm{in}$. Using these values in the equation we obtain

$$
\sigma_{\text {cyy }}=\frac{2 \times 1000 \mathrm{lb}}{[(2 \times 1.00 \mathrm{in.}-0.25 \mathrm{in.})(0.05 \mathrm{in.})]}=22860 \mathrm{psi}
$$

The corresponding strength from table I is $49800 \mathrm{psi}$. The margin of safety is

$$
\text { MOS }=\left(\begin{array}{lll}
49800 \text { ps } \dot{i} \\
\hline 22860 \text { psi }
\end{array}\right)-1=1.18 \quad 0 . K .
$$

Therefore, this composite bolted joint will not fail in wedge-type splitting.

\section{Shear-Out Failure Modes}

Shear-out failure modes in composite bolted joints are characterized by shear-out part of the laminate ahead of the bolt. A schematic depicting this 
failure mode is shown in figure $1(d)$ where the schematic used to derive the equation and the equation are also shown. The requisite variables to design against shear-out are: (1) the edge distance (e), (2) the laminate thickness $\left(t_{c}\right)$ and $(3)$ the laminate shear strength $\left(S_{c x y s}\right)$. The following example illustrates one use of the equation in figure $1(d)$.

Example 4. Calculate the shear-out stress for the composite bolted joint specified conditions in Example 1 with an edge distance of 1.0 in. To calculate the shear-out stress we first solve the equation in figure $1(d)$ for $S_{\text {cxys }}$ and replace $S$ by $\sigma$

$$
\sigma_{c y y}=\frac{F}{2 e t}
$$

where $F$ is $1000 \mathrm{lb}$, e is $1.0 \mathrm{in.}$, and $t_{c}$ is $0.05 \mathrm{in}$. Substituting these values in the equation we obtain

$$
\sigma_{c x y}=\frac{100016}{(2 \times 1.00 \times 0.05 \text { in. })}=10000 \mathrm{psi}
$$

The corresponding in-plane strength from table I is 38700 psi. The margin-of-safety is

$$
\operatorname{MOS}=\left(\frac{38700 \mathrm{psi}}{10000 \mathrm{psi}}\right)-1=2.87 \quad 0 . K
$$

Therefore, this composite bolted joint will not fail by shear-out. As a matter of fact, its edge distance can be decreased to $1 / 2$ in. and still have substantial MOS $(0.94)$.

\section{Tension With Shear-out Failure Modes}

Tension with shear-out failure modes are characterized by part net-section and part shear. A schematic of the failure mode is shown in figure 1 (e) where the schematic used to derive the equation and the equation are also shown. The requisite variables to design against this failure mode are: (1) laminate thickness, (2) net section dimension ( $w-d),(3)$ edge distance (e), (4) laminate tensile strength $\left(S_{C \times x T}\right)$, and (5) laminate in-plane shear strength ( $S_{\text {cxys }}$ ). The following example illustrates one use of the equation in figure $Y(e)$.

Example 5. Calculate the margin of safety of the composite bolted joint specified in Example 1 with bolt spacing 1.0 in. and edge distance 1.0 in. To calculate the MOS for this example we first calculate the bolt load ( $F$ ) to cause laminate failure and than we compare this to the specified value of 1000 1b. Repeating the equation:

$$
F=\frac{t_{c}\left[(w-d) S_{C x x T}+2 e S_{c x y S}\right]}{2}
$$


where $t_{c}$ is 0.05 in., $w$ is 1.0 in., d is $1 / 4$ in., e is 1.0 in., Scxx is 79200 psi (table I) and $S_{\text {cxys }}$ is 38700 psi (table I). Using these values in the equation

$F=\frac{0.05 \text { in. }[(1.00 \mathrm{in} .-0.25 \mathrm{in.}) \times 79200 \mathrm{psi}+2 \times 1.0 \mathrm{in.} \times 38700 \mathrm{psi}]}{2}=3420 \mathrm{lb}$

The corresponding specified load is $1000 \mathrm{lb}$. The margin-of-safety is

$$
\text { MOS }=\frac{342016}{100016}-1=2.42 \quad 0 . K .
$$

Therefore, this composite bolted joint will not fail by combined net-tension and shear-out.

Taken collectively these calculations show that local bearing is the most likely failure mode for this composite bolted joint. The interested reader can obtain insight by repeating the previous exercises using the strengths for the other two laminate configurations in table I.

\section{MULTI-BOLT COMPOSITE JOINTS}

Multi-bolt composite joints are required to transfer load between two adjacent panels or from a panel to its attachment. A representative schematic is shown in figure 2. Multi-bolt composite joints are designed by assuming that all the bolts in the joint are sharing equal load. In reality, the first row of bolts will usually transfer more load. However, any insignificant local bearing failure will redistribute the load to the next bolt row and so on. The example below illustrates the design procedure.

Example 6. Design a composite joint connecting a composite panel to a metallic plate attachment. Refer to the schematic in figure 2 . For this joint we only design the bolts for the composite panel. We assume that the metallic attachment has adequate strength. The composite panel is made from $[0 / \pm 45 / 90]_{S} A S / E$. The panels carries $2000 \mathrm{lb} / \mathrm{in}$. design tensile load and is $0.0 \overline{5} \mathrm{in}$. thick. We will use $1 / 4 \mathrm{in}$. diameter bolts. The bolt spacing is 6 bolt diameters ( $1.5 \mathrm{in.})$ and the edge distance is 4 bolt diameters (1.0 in.).

Step 1. Determine the load carried per bolt. The load carried per bolt is the bolt spacing times the panel load per inch.

$$
p \times N_{c x x}=1.5 \mathrm{in} . \times 2000 \mathrm{lb} / \mathrm{in} .3000 \mathrm{lb}
$$

Step 2. Determine the number of bolts per bolt row. Assuming first bearing failure mode, the number of bolts $N$ is determined from figure $1(a)$ :

$$
N=\frac{F}{\left(d t_{c} S_{c \times x c}\right)}
$$


where $F$ is $3000 \mathrm{lb}$ in.; $d=1 / 4$ in.; $t_{C}$ is $0.050 \mathrm{in.}$; and $S_{C \times x C}$ is 79700 psi. Using this values in the equation we calculate

$$
\begin{aligned}
& N=\frac{3000 \mathrm{lb} / \mathrm{in} .}{\left[(0.25 \text { in. })(0.050 \mathrm{in.})\left(79700 \mathrm{lb} / \mathrm{in.}{ }^{2}\right)\right]} \\
& N=3.01 \text { bolts, use } 3 \text { bolts }
\end{aligned}
$$

Check next net tension, the number of bolts in $N$ is from (fig. I(b))

$$
N=\frac{F}{[w-d] t_{C} S_{C X X T}}
$$

where $F=3000 \mathrm{lb}, w$ is $1.50 \mathrm{in.;} d$ is $0.25 \mathrm{in.;} t_{c}=0.05$ in.; and $S_{C \times x T}$ is $79200 \mathrm{lb} / \mathrm{in} .{ }^{2}$. Using these values in the equation we calculate

$$
\begin{aligned}
& N=\frac{3000 \mathrm{lb}}{\left[(1.5 \mathrm{in} .-0.25 \mathrm{in.})\left(0.050 \mathrm{in} .79200 \mathrm{lb} / \mathrm{in.}{ }^{2}\right)\right]} \\
& N=0.61 \text { bolts, use } 1 \text { bolt }
\end{aligned}
$$

Therefore, local bearing is more severe than net tension.

Step 3. Check the other failure modes for the edge and corner bolts.

First Row Center Bolt in Shear-Out

The shear stress is calculated from the equation (fig. 1(d)).

$$
\sigma_{c x x}=\frac{F}{\left(2 e t_{c}\right)}
$$

where $F$ is $1000 \mathrm{lb}$; e is $1.0 \mathrm{in.;}$ and $t_{c}$ is $0.05 \mathrm{in}$. Using these values in the equation, we calculate

$$
\begin{gathered}
\sigma_{\text {cxx }}=\frac{1000 \mathrm{lb}}{(2 \times 1.0 \mathrm{in.} \times 0.05 \mathrm{in.})}=10000 \mathrm{lb} / \mathrm{in}^{2} \\
10000 \mathrm{lb} / \mathrm{in} .^{2}<38700 \mathrm{lb} / \mathrm{in}^{2} \text { o.k. }
\end{gathered}
$$

and

$$
\text { MOS }=\frac{38700 \mathrm{lb} / \mathrm{in.}^{2}}{10000 \mathrm{lb} / \mathrm{in.}^{2}}-1=2.87
$$

First Row Center Bolt in Wedge-Type Splitting

The transverse tensile stress from the equation in figure $l(c)$ is:

$$
\sigma_{c y y}=\frac{2 F}{\left[(2 e-d)^{t} c\right]}
$$


Substituting respective numerical values, we calculate

$$
\begin{aligned}
\sigma_{\text {cyy }}= & \frac{2 \times 1000 \mathrm{lb}}{[(2 \times 1.0 \mathrm{in} .-0.25 \mathrm{in} .) \times 0.05 \mathrm{in} .]}=32000 \mathrm{lb} / \mathrm{in} .{ }^{2} \\
& 32000 \mathrm{lb} / \mathrm{in} .{ }^{2}<49800 \mathrm{lb} / \mathrm{in}^{2} \text { o.k. }
\end{aligned}
$$

and

$$
\begin{aligned}
& \text { MOS }=\frac{49800 \mathrm{lb} / \mathrm{in.}^{2}}{32000 \mathrm{lb} / \mathrm{in.}^{2}}-1=0.56 \\
& \text { Corner Bolt in Tension with Shear-Out }
\end{aligned}
$$

The force required to induce tension with shear-out in the corner bolt is calculated from (fig. $1(e)$ ) where $w=p$

$$
F=\frac{t_{c}\left[(p-d) S c_{x x T}+2 e S_{c x y S}\right]}{2}
$$

Using respective numerical values in the equation, we calculate

$$
\begin{gathered}
F=0.05 \text { in. }\left[(1.50 \mathrm{in} .-0.25 \mathrm{in} .) \times 79200 \mathrm{lb} / \mathrm{in} .{ }^{2}\right. \\
\left.+2 \times 1.00 \mathrm{in} .38700 \mathrm{lb} / \mathrm{in} .{ }^{2}\right] / 2=4410 \mathrm{lb} \\
4410 \mathrm{lb}>1000 \mathrm{lb} \quad 0 . \mathrm{K} .
\end{gathered}
$$

and

$$
\text { MOS }=\left(\frac{44101 b}{100016}\right)-1=3.41
$$

Therefore, use three $1 / 4$ in. bolts per column at 1.50 in. on centers to join the composite panel to the metal attachment (fig. 2).

\section{GENERAL DISCUSSION}

Several other factors influence composite bolted joint design. These include (1) bypass load, (2) load transferred through friction, (3) cyclic load, (4) temperature effects, (5) moisture effects, (6) biaxial loads, (7) flat-wise compression due to bolt torqueing, and ( 8 ) flat-wise local bearing at the edge of bolts heads, nuts, or washers. A brief discussion on each of these factors follow.

Bypass load. - The bypass load is that load that bypasses the bolt and must be resisted by bolts following the bolt being bypassed. This is important in multi-bolted joints and was implied in the multi-bolted joint 
designed discussed previously. They key question is how much of the load is bypassed. This is not as simple a problem as it may seem. Usually innovative use of finite element analysis is needed to determine the bypass load.

Load transferred through friction. - The load transferred through friction reduces the load transferred through the bolt. This load can be substantial. It depends on the through-the-thickness compressive stress and the coefficient of friction between (1) bolt head, washer or nut and composite and (2) between the composite panel surfaces or composite panel metallic attachment surface. The load transferred through friction may not be dependable in situations where there are temperature fluctuations and large differences in the thermal expansion coefficients of the composite and the bolt. The load transferred through friction increases the bearing load capacity compared to that predicted using laminate compression strength in general (ref. 7).

Cyclic load effects. - Cyclic load effects generally degrade the laminate strengths. The degree of degradation depends on the number of cycles, cyclic stress range, mean stress, and environmental conditions. Procedures for estimating some of these strength degradations are described in reference 6 . The degraded strengths are used in the equations in figure 1 to design/analyze the bolted joint.

Temperature effects. - The temperature effects influence the laminate strengths. Procedures for evaluating this influence are described in reference 6 . The modified strengths are used in the equations in figure 1 to design/analyze the bolted joint.

Moisture effects. - Moisture effects are handled the same way as temperature effects. The combined moisture/temperature effects on laminate strength are also estimated using the procedures in reference 6 .

Biaxial loads. - In biaxial load cases (for example, $x$ and $y$ loads) the bolted joint is designed to transfer both loads. The assumption made is that each load is transferred independently. The equations in figure 1 are applied individually to each $x$ and $y$ loads. Other effects are incorporated as was described previously.

Flat-wise compression. - Flat-wise compression is induced by torqueing the bolt to a predetermined value in order to prevent slippage between panels. The amount of torque used is determined from the amount of flat-wise compression required. Calibration experiments are generally conducted to develop flat-wise compression versus torque curves which are used to specify the torque to be used. The torque can also be estimated from elementary mechanics and energy balance concepts.

Flat-wise load bearing at the edges of bolt-heads, nuts, or washers. These are usually caused by (1) uneven joint, (2) local bending - prominent in single lap joints, and (3) combinations. This stress value is determined by knowing the bolt torque, the amount of bending, and the environmental conditions. Estimates are obtained using elementary mechanics concepts. Accurate evaluations are determined by innovative use of finite element analysis. 
Many of the factors discussed previously have been investigated, in part, and reported in the technical literature. For example the various failure modes in composites are discussed extensively in reference 7 . The edge distance effect on net tension failure and bearing stress have been investigated and reported in reference 7 . The local stress distribution in the periphery of the bolt hole due to different types of bolts is discussed in reference 4 where the effect of clearance on the bearing (radial) and hoop stress are also discussed. The fatigue effects on composite joints is discussed in reference 7 . The effects of (1) bolt diameter to thickness ratio $(D / t)$, (2) bolt spacing to diameter ratio, and (3) edge distance to bolt diameter ratio are discussed in reference 3 . Recommended allowables for select $D / t$ ratios and for several composites are included in reference 3 where recommended clearances, edge and side distances are also included.

Design of composite joints requires considerable care. The methods described here are adequate for the preliminary design phase only. These methods must be complemented with appropriate finite element analyses and strategic experiments for final design. The references cited provide a variety of guidelines for selecting appropriate analyses and experiments.

\section{SUMMARY}

Simplified methods to design/analyze composite bolted joints have been presented. The typical failure modes are discussed and respective equations to design for these failure modes are presented. The methods are illustrated by applying them to single and multi-bolt composite joint designs. Various factors affecting composite joint design are summarized. Select references are cited where more extensive discussions on specific aspects of bolted composite joints can be found. The methods and sample calculations presented in this paper are suitable for the preliminary design phase. The methods need to be complemented with appropriate finite element analyses and selective testing for the final design phase.

\section{REFERENCES}

1. K.T. Kedward, Ed., Joining of Composite Materials, ASTM STP 749, ASTM, Philadelphia, PA, 1981.

2. Jointing in Fiber Reinforced Plastics, IPC Science and Technology Press Ltd., Surrey England, 1978.

3. S.J. Dasting, "Joining and Machining Technique," Handbook of Composites, G. Lubin, Ed., Von Nostrand, New York, 1982, Chapter 22.

4. M.W. Hyer and E.C. Klang, "Contact Stresses in Pin-Loaded Orthotropic Plates," Int. J. Solids Struct., vol. 21, no. 9, Sept. 1985, pp. 957-975.

5. P.L.N. Murthy and C.C. Chamis, "Integrated Composite Analyzer (ICAN) Users and Programmers Manual," NASA TP-2515, 1986.

6. C.C. Chamis and C.A. Ginty, "Composite Structural Durability and Damage Tolerance: Simplified Predictive Methods," NASA TM-100179, 1987. 
7. R.L. Ramkumar, and E.W. Tossavainen, "Strength and Lifetime of Bolted Laminates," Fatigue in Mechanically Fastened Composite and Metallic Joints, ASTM STP 927, J.M. Potter, Ed., ASTM, Philadelphia, 1986, pp. 251-273. 
APPENDIX

DESIGN VARIABLES FOR COMPOSITE BOLTED JOINTS

Laminate (composite) bolted connections are mainly controlled by two groups of design variables, those for the bolts and those for the laminates, as follows:

I. Bolt design variables

1. Bolt diameter (d)

2. Washer, bolt-head or nut diameter $\left(d_{w}\right)$

3. Bolt material and threads per inch

4. Bolt strength (static, cyclic), tension and shear (single, double) tensile yield strength ( $S_{\text {by }}$ ) for bolt pretension shear yield strength (SbyT) for bolt pretension oftentimes the bolt strengths are specified by the supplier

5. Thermal expansion coefficients

II. Laminate design variables

1. Laminate strengths (static, cyclic, environmental)

a. Bearing - axial compressive strength $\left(S_{C \times x C}\right)$

b. Axial tensile strength $\left(S_{C \times x T}\right)$

c. Transverse tensile strength ( $S_{\text {cyy }}$ )

d. Through-the thickness (flat-wise) compressive strength $\left(S_{C Z z C}\right.$ ) for local bearing due to bolt pretension and/or joint local bending

2. Laminate thickness $\left(t_{c}\right)$ - multiples of basic laminate configurations for which the laminate strengths in II-l are known

3. Laminate edge distances

a. Axial direction (e)

b. Transverse direction $(w-d) / 2$

c. Bolt spacing $(W)$ or pitch $(p)$ - both width-wise (row) and span-wise (column). The spacing can be square, rectangular, or staggered.

4. Laminate moduli and Posison's ratios

5. Laminate thermal and moisture expansion coefficients

6. Temperature and moisture effects on all properties

The laminate properties needed for bolted joint design are either available from tests or can be predicted using the computer codes such as ICAN (ref. 5) as were the properties in table I.

III. Safety factors

Safety factors are usually established for specific designs. Two cases generally exist in the preliminary design phases

1. Design loads given - for this case no safety factors are required and margins of safety of 0.15 or greater on failure modes are typically acceptable.

2. Specified or ultimate loads given - nominal factors of safety are: (1) 2 for loads for the composite and (2) 1.5 on the yield stress for the bolts. Additional safety factors may be required for cyclic loads. 
TABLE I. PREDICTED FRACTURE STRESSES FOR SELECT LAMINATES ${ }^{a}$

[AS/E AT 0.6 FVR.]

\begin{tabular}{|l|c|c|c|}
\hline \multirow{2}{*}{$\begin{array}{c}\text { Stress } \\
\text { type }\end{array}$} & \multicolumn{3}{|c|}{ Laminate/fracture stress, ksi } \\
\cline { 2 - 4 } & {$[(0 /+45 / 0 / 90)]_{\mathrm{S}}$} & {$\left[\left(0_{3} / \pm 80\right)\right]_{\mathrm{S}}$} & {$\left[\left(0 /+3-/ 0^{\mathrm{S}} /-30 / 0\right)\right]_{\mathrm{S}}$} \\
\hline$S_{\text {cxxT }}$ & 79.2 & 94.8 & 129.3 \\
$S_{\text {cxxC }}$ & 79.7 & 99.1 & 70.5 \\
$S_{\text {cyyT }}$ & 49.8 & 61.0 & 6.3 \\
$S_{\text {cyyC }}$ & 51.5 & 67.8 & 14.7 \\
$S_{\text {cxyS }}$ & 38.7 & 13.1 & 20.1 \\
\hline
\end{tabular}

apredicted using the ICAN computer code (ref. 5).

Notation:

$S_{c} \quad$ Laminate strength

$x, y, z$ Direction $(x, y$ - laminate plane; $z$ - thickness

$T, C, S$ Tension, compression, shear

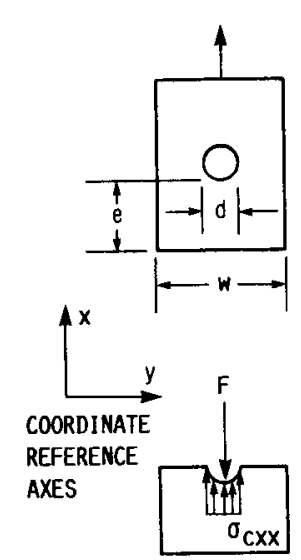

(a) LOCAL BEARING.
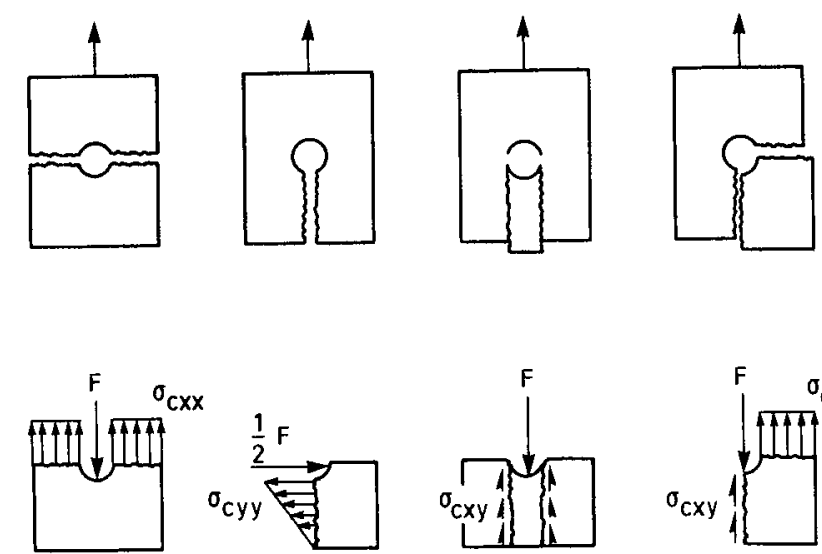

(b) NET TENSION. (c) WEDGE-TYPE
SPLITTING.

(d) SHEAR-OUT.

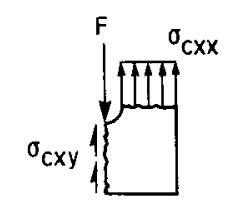

AT FRACTURE: BOLT FORCE F =

${ }^{d t} c^{s} c x x c$

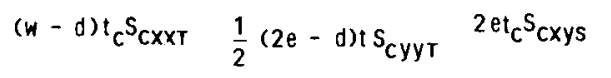

$$
\begin{array}{r}
\frac{t c}{2}\left[(w-d) s_{C x x T}\right. \\
\left.+2 e s_{c x y s}\right]
\end{array}
$$

FIGURE 1. - COMPOSITE BOLTED JOINTS - FAILURE MODES AND RESPECTIVE EQUATIONS. 


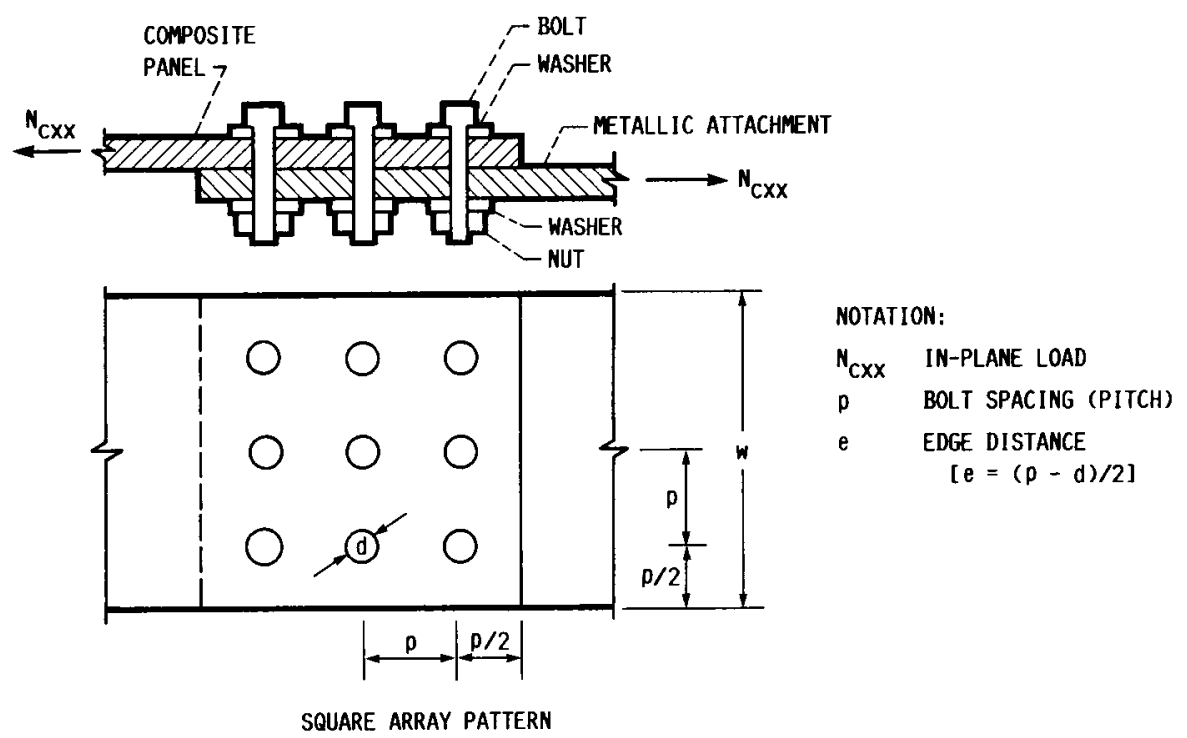

FIGURE 2. - SCHEMATIC OF MULTI-BOLT COMPOSITE JOINT. 


\begin{tabular}{|c|c|c|c|c|}
\hline \multirow{2}{*}{ 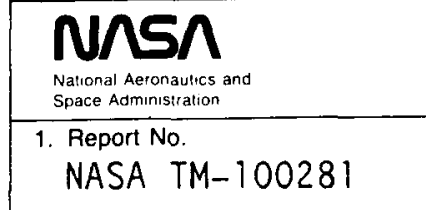 } & \multicolumn{4}{|c|}{ Report Documentation Page } \\
\hline & \multicolumn{2}{|c|}{ 2. Government Accession No. } & \multicolumn{2}{|c|}{ 3. Recipient's Catalog No. } \\
\hline \multirow{3}{*}{\multicolumn{3}{|c|}{$\begin{array}{l}\text { 4. Title and Subtitle } \\
\text { Simplified Procedures for Designing } \\
\text { Composite Bolted Joints }\end{array}$}} & \multirow{2}{*}{\multicolumn{2}{|c|}{ 5. Report Date }} \\
\hline & & & & \\
\hline & & & \multicolumn{2}{|c|}{ 6. Performing Organization Code } \\
\hline \multirow[t]{2}{*}{$\begin{array}{l}\text { 7. Author(s) } \\
\text { Christos C. Chamis }\end{array}$} & & & \multicolumn{2}{|c|}{$\begin{array}{l}\text { 8. Performing Organization Report No. } \\
\text { E-3922 }\end{array}$} \\
\hline & & & \multicolumn{2}{|l|}{$\begin{array}{l}\text { 10. Work Unit No. } \\
505-63-11\end{array}$} \\
\hline \multirow{2}{*}{\multicolumn{3}{|c|}{$\begin{array}{l}\text { 9. Performing Organization Name and Address } \\
\text { National Aeronautics and Space Administration } \\
\text { Lewis Research Center } \\
\text { Cleveland, Ohio } 44135-3191\end{array}$}} & \multirow{2}{*}{\multicolumn{2}{|c|}{ 11. Contract or Grant No. }} \\
\hline & & & & \\
\hline \multicolumn{3}{|c|}{ 12. Sponsoring Agency Name and Address } & \multicolumn{2}{|c|}{$\begin{array}{l}\text { 13. Type of Report and Period Covered } \\
\text { Technical Memorandum }\end{array}$} \\
\hline \multicolumn{3}{|c|}{$\begin{array}{l}\text { National Aeronautics and Space Administration } \\
\text { Washington, D.C. } 20546-0001\end{array}$} & \multicolumn{2}{|c|}{ 14. Sponsoring Agency Code } \\
\hline \multicolumn{5}{|c|}{$\begin{array}{l}\text { 15. Supplementary Notes } \\
\text { Prepared for the 43rd Annual Conference of the Society of the Plastics Industry, } \\
\text { Cincinnati, Ohio, February } 1-5,1988 \text {. }\end{array}$} \\
\hline \multicolumn{5}{|c|}{$\begin{array}{l}\text { 16. Abstract } \\
\text { Simplified procedures (methods) are described to design/analyze single and } \\
\text { multi-bolt composite joints. Numerical examples illustrate the use of these } \\
\text { methods. Factors affecting composite bolted joints are summarized. References } \\
\text { are cited where more detailed discussion are presented on specific aspects of } \\
\text { composite bolted joints. Design variables associated with these joints are sum- } \\
\text { marized in the appendix. }\end{array}$} \\
\hline \multicolumn{2}{|c|}{$\begin{array}{l}\text { 17. Key Words (Suggested by Author(s)) } \\
\text { Fiber composites; Il lustrative examples; } \\
\text { Design; Analysis; Failure modes; } \\
\text { Bearings; Net tension; Splitting; } \\
\text { Shear-out; Combined; Composite strengths }\end{array}$} & \multicolumn{3}{|c|}{$\begin{array}{l}\text { 18. Distribution Statement } \\
\text { Unclassified - Un } 1 \text { imited } \\
\text { Subject Category } 24\end{array}$} \\
\hline $\begin{array}{l}\text { 19. Security Classif. (of this report) } \\
\text { Unclassified }\end{array}$ & $\begin{array}{l}\text { 20. Security Classit. (of this } \\
\text { Unclass if }\end{array}$ & & $\begin{array}{c}\text { 21. No of pages } \\
14\end{array}$ & $\begin{array}{r}\text { 22. Price }{ }^{*} \\
\mathrm{~A} 02\end{array}$ \\
\hline
\end{tabular}

